OPEN ACCESS

Edited by:

Pierluigi Porcu,

Sidney Kimmel Cancer Center,

United States

Reviewed by:

Giuseppe Alberto Palumbo

University of Catania, Italy

Lindsay Wilde,

Sidney Kimmel Cancer Center, United States

*Correspondence:

Ahmad Ibrahim

ahmad_o_ibrahim@hotmail.com

Specialty section

This article was submitted to

Hematologic Malignancies,

a section of the journa

Frontiers in Oncology

Received: 21 May 2020 Accepted: 09 February 2021

Published: 15 March 2021

Citation:

Ibrahim A, Noun P, Khalil $C$ and

Taher A (2021) Changing

Management of Hematological

Malignancies With COVID-19:

Statement and Recommendations of the Lebanese Society of Hematology

and Blood Transfusion.

Front. Oncol. 11:564383.

doi: 10.3389/fonc. 2021.564383

\section{Changing Management of Hematological Malignancies With COVID-19: Statement and Recommendations of the Lebanese Society of Hematology and Blood Transfusion}

\author{
Ahmad Ibrahim $^{1,2,3,4 *}$, Peter Noun ${ }^{5,6}$, Charbel Khalil ${ }^{7,8}$ and Ali Taher ${ }^{4,9,10}$ \\ ${ }^{1}$ Division of Hematology-Oncology, Department of Medicine, Lebanese and Arab Universities, Beirut, Lebanon, ${ }^{2}$ Cancer \\ Center and Bone Marrow Transplantation (BMT) Program at Middle East Institute of Health, Bsalim, Lebanon, ${ }^{3}$ Bone Marrow \\ Transplantation (BMT) Program at Makassed University Hospital, Beirut, Lebanon, ${ }^{4}$ Lebanese Society of Hematology and \\ Blood Transfusion, Beirut, Lebanon, ${ }^{5}$ Division of Pediatrics, Balamand University, Beirut, Lebanon, ${ }^{6}$ Division of Pediatric \\ Hematology-Oncology, Saint Georges University Medical Center, Beirut, Lebanon, ${ }^{7}$ Bone Marrow Transplantation (BMT) \\ Program at Middle East Institute of Health University Hospital, Beirut, Lebanon, ${ }^{8}$ Faculty of Pharmacy, Saint Joseph \\ University, Beirut, Lebanon, ${ }^{9}$ Division of Hematology-Oncology, Department of Medicine, American University of Beirut, \\ Beirut, Lebanon, ${ }^{10}$ Cancer Center of the American University of Beirut, Beirut, Lebanon
}

COVID-19 caused by SARS-Cov-2 is a devastating infection in patients with hematological malignancies. In 2018, the Lebanese Society of Hematology and Blood Transfusion (LSHBT) updated the guidelines for the management of hematological malignancies in Lebanon. In 2019, it was followed by a second update. Given the rapidly changing evidence and general situation for COVID-19, the LSHBT established some recommendations and suggestions for the management of the patients with hematological malignancies taking into account the Lebanese condition, economic situation, and the facts that SARS-Cov-2 infection has apparently been devastating. In this article we present recommendations and proposals to reduce or to manage SARS-Cov-2 infection in the patients with myeloid and lymphoid hematological malignancies.

Keywords: SARS-Cov-2 infection, LSHBT, hematological malignancies, myeloid, lymphoid

\section{INTRODUCTION}

With almost 101.5 million of declared infected persons including at least 2.18 million deaths, COVID-19 caused by SARS-Cov-2 is a devastating infection particularly in patients with hematological malignancies (1).

In Lebanon with almost $290 \mathrm{~K}$ persons were detected positive and 2,553 died, the novel corona virus pandemic which seem to be less devastating is spreading (2). 
Patients with hematological malignancies are treated in Lebanon in different types of structures having a heterogeneous expertise, including public and private academic and nonacademic hospitals, military hospitals and clinics. On the other hand, coverage of the management is heterogeneously assured by the Lebanese ministry of public health, the national social security system, the army, the national cooperative system and the private insurances. Do note that almost $10-15 \%$ of the patients have to pay to be treated. Currently, there are four bone marrow transplantation units including three which perform allogeneic and autologous transplants and are European Society for Blood and Marrow Transplantation (EBMT) members and one which only performs autologous transplantation. CART-cell therapy is still not available in the country.

The Lebanese Society for Hematology and Blood Transfusion (LSHBT) presented in 2018 to the Lebanese ministry of public health which updated in 2019, with the help of United Nations Development program/TOKTEN (UNDP). An update of national guidelines for hematological diseases including hematological malignancies in order to harmonize patients management (3). In view of the rapidly changing evidence and general situation for COVID-19, the LSHBT proposed some recommendations and suggestions for the management of the patients with hematological malignancies in the era of SARS-Cov-2 infection. These recommendations collected from different international societies guidelines (4-8) were adapted to the Lebanese condition.

The aim of this approach is to assist Lebanese hematologists and oncologists in their clinical decision making and management of the patients; but, it remains the responsibility of each physician to decide the appropriate medical management and advice for the patients.

In this article we present recommendations and proposals to reduce or to manage SARS-Cov-2 infection in the patients with myeloid and lymphoid hematological malignancies.

\section{GENERAL RECOMMENDATIONS}

A strict triage upon access to care must be done. COVID-19 nasopharyngeal swab of the patients must be performed and results obtained before admission to the hematology unit. It is recommended to avoid sending a possible COVID-19 patient, particularly immunocompromised, to emergency room. In case of urgent admission, care should be taken similarly to patient infected in a specific COVID-19 unit until obtaining the result of PCR. If PCR is negative, the patient can be transferred to the hematology unit. Symptomatic and/or PCR positive patients must be admitted to a specific COVID-19 unit in close collaboration with ICU. So if possible, it is necessary to create a specific hematology unit for COVID-19 positive patients with dedicated personnel.

Patients should avoid getting infected by strict adherence to hand hygiene, mask use (surgical, FFP2/3), physical distancing and home isolation. It is preferable to educate carefully and provide written interactive measures.
It is recommended to avoid crowded clinics by deferring regular routine follow-up and particularly over-the phone consultations, telemedicine or telehealth if available.

It is also necessary to consider limitation of hospital admissions or visits by preferring oral or S/C medications or delaying treatment if possible.

Visits of the patients in the hospital must be reduced at maximum or avoided if possible.

Because important effort should be done in order to prevent COVID-19 in healthcare workers, appropriate distancing and use of mask are necessary, so it is recommended to educate the staff on the use of PPE. Swab for SARS-Cov-2 must be done for any symptomatic healthcare worker or exposed to SARS-Cov2 positive person. If any symptom appears in any healthcare worker, he or she should stay home isolated.

Inclusion in clinical trials should be postponed if possible and follow-up of patients included should be modified in order to reduce hospital visits and tests.

In Lebanon, classical cytogenetic and basic molecular testing is available and affordable for the majority of the patients with hematological malignancies. Flow cytometry for diagnosis and residual disease analysis is also available and done for quasi all patients. Next generation sequencing can be performed in the country but still not routinely performed in the clinical practice. It is necessary to develop these genomic analyses which are helpful for diagnosis, prognosis and management of the patients with hematological malignancies in order to facilitate the decision of the appropriate strategy for induction and consolidation therapy particularly in the SARS-Cov-2 pandemic $(9,10)$.

In Lebanon, drug are provided to the patients by the hospitals, but also by other structures like ministry of health, the army and related, the cooperative system etc... practically on monthly basis. So, it is necessary to create a homogenous system in order to deliver drugs for 2 or 3 months to limit patient's visits.

\section{RECOMMENDATIONS TO REDUCE SARS-Cov-2 INFECTION IN MYELOID HEMATOLOGICAL MALIGNANCIES}

\section{Acute Myeloblastic Leukemia}

Induction and consolidation therapy in Acute Myeloblastic Leukemia (AML) patients could induce infectious complications because of severe and prolonged neutropenia. Infections are in most cases due to bacterial and/or fungal microorganisms; however, viral infections could occurred, in particular due to respiratory virus, with well-documented cases of severe and fatal respiratory infection in SARS-Cov-2 hematologic patients. So there is a need for changing therapeutic approach in some patients.

Table 1 summarized the recommendations for AML.

\section{Testing for SARS-Cov-2}

Testing should be performed for all newly diagnosed AML patients, and at the start of the next treatment cycle. Patients with fever and/or other symptoms related to SARS-Cov-2 
TABLE 1 | Acute myeloblastic leukemia

\begin{tabular}{|c|c|}
\hline Testing & $\begin{array}{l}\text { - For newly diagnosed patients } \\
\text { - If fever and/or other symptoms related to SARS-Cov-2 } \\
\text { infection } \\
\text { - Donor and recipient before allogeneic transplant }\end{array}$ \\
\hline $\begin{array}{l}\text { Induction (AML } \\
\text { non-APL) }\end{array}$ & $\begin{array}{l}\text { - Consider starting } \mathrm{HU} \text { in proliferative } \mathrm{AML} \text { which helps to } \\
\text { delay induction if necessary } \\
\text { - Eligible patients: } 3+7 \text { regimen } \\
\text { - Non-eligible patients: hypomethylating agents } \\
\text { ( } \pm \text { Venetoclax) } \\
\text { - Targeted therapy for FLT3 or IDH } 1 / 2 \text { mutations should } \\
\text { be given } \\
\text { - Mylotarg (Anti CD33) for CBF AML patients } \\
\text { - G-CSF to shorten neutropenia } \\
\text { - Lowering transfusion episodes, by lowering thresholds } \\
\text { for } \mathrm{Hb}(<7 \mathrm{~g} / \mathrm{dl}) \text { and platelets }\left(<10 \times 10^{9} / \mathrm{L}\right)\end{array}$ \\
\hline $\begin{array}{l}\text { Consolidation (AML } \\
\text { non-APL) }\end{array}$ & $\begin{array}{l}\text { - Eligible patients in CR after induction: reduction of the } \\
\text { doses and cycles of cytosine-arabinoside } \\
\text { - Non-eligible patients in CR after induction: } \\
\text { hypomethylating agents ( } \pm \text { Venetoclax) } \\
\text { - G-CSF and transfusion as for induction }\end{array}$ \\
\hline $\begin{array}{l}\text { Relapsed/refractory } \\
\text { (AML non-APL) }\end{array}$ & $\begin{array}{l}\text { - Eligible patients: salvage intensive re-induction therapy } \\
\text { - Non-eligible patients: and if non-proliferative AML, } \\
\text { consider hypomethylating agents ( } \pm \text { Venetoclax) } \\
\text { - Consider starting HU in proliferative AML } \\
\text { - Targeted therapy (anti FLT3 or IDH1/2) should be given } \\
\text { - G-CSF and transfusion as for induction }\end{array}$ \\
\hline APL & $\begin{array}{l}\text { - Lower-risk: ATRA and ATO as per standard treatment } \\
\text { - High-risk: ATRA and ATO added to cytoreductive } \\
\text { chemotherapy as per standard treatment } \\
\text { - If ATO not available, ATRA and anthracyclines }\end{array}$ \\
\hline $\begin{array}{l}\text { Allogeneic } \\
\text { transplant }\end{array}$ & - No delay \\
\hline
\end{tabular}

infection should have an additional test at any time. Donor and recipient for allogeneic transplant should also be tested before the procedure.

\section{Induction Therapy for AML (Non-APL)}

Intensive induction chemotherapy should still be offered for eligible patients with $3+7$ (anthracyclines for 3 days and cytosine- arabinoside for 7 days) or similar regimens (11). Fludarabine combination should be avoided because of the deep immunosuppression effect of this drug. For the other patients, non-chemotherapeutic induction could be hypomethylating agents with or without low doses of cytosine-arabinoside (12). Adding of venetoclax to hypomethylating agents can be considered but at lower doses of venetoclax because the combination could induce long phases of aplasia (12-14). This combination can also be administered as alternative to chemotherapy in patients with positive NPM1 mutation because of high rate of durable complete remission (CR) obtained (15). Furthermore, venetoclax based regimens can be given for any non-CBF elderly patient ( $>60$ year-old), or patient over 50 yearold with MPN1 or IDH1/2 mutations (14).

Mylotarg (antiCD33) can be administered to CBF AML patients in combination with $3+7$ regimen due to the significant improvement of survival in these patients with this combination.
Myelotarg is omitted from chemotherapy combination for intermediate- and high-risk patients $(16,17)$.

Other targeted therapies (e.g., Anti FLT3 or anti IDH1/2) when indicated should be administered.

\section{Consolidation Therapy for AML (Non-APL)}

For eligible patients with CR after induction chemotherapy, consolidation with high-dose cytosine-arabinoside based regimens should be offered, but reducing the dose of cytosinearabinoside (e.g., $1.5 / \mathrm{m}^{2}$ instead of $3 \mathrm{~g} / \mathrm{m}^{2}$ per dose) and decreasing the number of cycles to $2-3$ instead of four are considered, since randomized studies showed disease-freesurvival (DFS) advantage only in favorable cytogenetic risk patients at higher doses $\left(3 \mathrm{~g} / \mathrm{m}^{2}\right)$ of cytosine-arabinoside (18). For the other patients, hypomethylating agents could be given.

\section{Relapse/Refractory AML (Non-APL)}

Standard intensive regimens are used for eligible patients. For the other patients, and if the disease is not proliferative reinduction therapy could be temporarily postponed. Hydroxyurea (HU) could be given if the disease in proliferation awaiting re-induction therapy.

Targeted therapy (hypomethylating agents, venetoclax, anti FLT3 or anti IDH1/2, etc...) can be administered.

\section{Supportive Care}

Because of difficulties and possible shortages in blood bank supplies, lowering transfusion episodes, by lowering transfusion thresholds (e.g., $7 \mathrm{~g} / \mathrm{dL}$ for $\mathrm{Hb}, 10 \times 10^{9} / \mathrm{L}$ for platelets) should be considered for patients without symptoms due to anemia or thrombocytopenia. G-CSF can be administered to shorten neutropenia.

\section{Allogeneic Hematopoietic Stem Cell Transplantation}

Allogeneic transplant should not be delayed. Cryopreservation of donor cells prior to starting the procedure should be considered.

\section{Acute Promyelocytic Leukemia}

All patients with low-risk APL should be treated when available with all transretinoic acid (ATRA) and arsenic trioxide (ATO) as per standard treatment. For high-risk patients, ATRA and ATO added to cytoreduction therapy should be given as per standard regimens. If ATO is not available, ATRA could be added to chemotherapy (e.g., anthracycline) (19).

\section{Myelodysplastic Syndromes}

Patients with Myelodysplastic Syndromes (MDS) who are lymphopenic or neutropenic or have undergone allogeneic transplant are at high-risk after contracting SARS-Cov-2 to get serious complications.

Table 2 summarized the recommendations for MDS.

\section{Testing for SARS-Cov-2}

Testing should be performed for all newly diagnosed patients, then at the start of the next treatment cycle. Patients with fever and/or other symptoms related to SARS-Cov-2 infection should have an additional test at any time. Donor and recipient 
TABLE 2 | Myelodysplastic syndromes.

\begin{tabular}{|c|c|}
\hline Testing & $\begin{array}{l}\text { - For newly diagnosed patients } \\
\text { - If fever and/or other symptoms related to SARS-Cov2 } \\
\text { infection } \\
\text { - Donor and recipient before allogeneic transplant }\end{array}$ \\
\hline Initial therapy & $\begin{array}{l}\text { - Higher-risk: hypomethylating agents ( } \pm \text { venetoclax) } \\
\text { - Lower-risk: agent to reduce transfusion needs (ESA, } \\
\text { lenalidomide) } \\
\text { - Del } \mathbf{( 5 q )} \text { syndrome: lenalidomide } \\
\text { - Lowering transfusion episodes if possible, by lowering } \\
\text { the threshold for } \mathrm{Hb}(<7 \mathrm{~g} / \mathrm{dl}) \text { and platelets }(<10 \times \\
\left.10^{9} / \mathrm{L}\right) \\
\text { - G-CSF to shorter neutropenia } \\
\text { - Transfusion as for AML }\end{array}$ \\
\hline Relapsed/refractory & - Management on a case-by-case basis \\
\hline Allogeneic transplant & - No delay \\
\hline
\end{tabular}

for allogeneic transplant should also be tested before starting the procedure.

\section{Initial Therapy}

Patients with high-risk MDS can receive hypomethylating agents with or without venetoclax, without dose adjustment (20).

Patients with lower-risk MDS, therapy that reduces transfusion needs (erythropoiesis stimulating agents, lenalidomide...) should be used (20). Luspatercep, an erythroid maturation agent, not available currently in Lebanon, but approved by the FDA for the treatment of anemia failing an erythropoiesis stimulating agent and requiring two or more red blood cell (RBC) units over 8 weeks in adult patients with very low- to intermediate-risk MDS with ring sideroblasts (MDS-RS) or with MDS/MPNs with ring sideroblasts and thrombocytosis (MDS/MPN-RS-T), can be used if the patient has the drug on his or her own (21).

For patients with del (5q) syndrome, lenalidomide can be given (20).

Because of difficulties and possible shortages in blood bank supplies, lowering transfusion episodes by lowering transfusion thresholds (e.g., $7 \mathrm{~g} / \mathrm{dl}$ for $\mathrm{Hb}, 10 \times 10^{9} / \mathrm{L}$ for platelets) should be done for patients without symptoms due to anemia or thrombocytopenia. G-CSF can be given to shorten neutropenia.

\section{Relapsed/Refractory Patients}

Therapy should be decided on a case-by-case basis.

\section{Allogeneic Hematopoietic Stem Cell Transplantation \\ Efforts should be made not to delay admission for allogeneic transplant. Cryopreservation of donor cells prior to the procedure is preferable.}

\section{Chronic Myelogenous Leukemia}

Table 3 summarized the recommendations for Chronic Myelogenous Leukemia (CML).

\section{Testing for SARS-Cov-2}

Testing should be performed for all newly diagnosed CML patients. Patients with fever and/or other symptoms related to SARS-Cov-2 infections should have an additional test at any time. Donor and recipient for allogeneic transplant should also be tested before starting the procedure.

\section{Chronic Phase}

Neither chronic phase CML nor BCR-ABL tyrosine kinase inhibitors (TKIs) induce significant immune suppression and there has been no data suggesting that CML patients in first chronic phase may be at higher risk of infection by the novel coronavirus than the general population. Based on that, newly diagnosed CML treatment choice does not need to change with no delay of introduction of TKIs; however, during the first 3 months of TKI therapy, extreme caution is advised because myelosuppression may occur in some patients and regular control of blood count (every 1-2 weeks) is recommended. In order to avoid severe pancytopenia, in particular neutropenia, dose interruptions or reductions should be done on a case- to case basis (22).

For CML patients already on therapy with TKIs, treatment should not be changed because interruption of TKIs may lead to loss of response and progression or relapse (22).

Patients in remission on regular PCR monitoring should continue this schedule. To minimize patient travel and exposure, remote testing (test done at home) is to be considered.

Careful attention should be made to metabolic, cardiovascular or pulmonary side effects induced by some TKIs which might complicate SARS-Cov-2 infection (19).

In patients facing resistance or intolerance to current TKI, it is not recommended to delay a change in therapy as outcome may be worsened (22).

Patients who have entered treatment-free-remission (TFR) for $<6-12$ months and requiring more frequent monitoring, as often as monthly, have to continue if it is possible; however, a decrease in frequency can be considered every 1.5-2 months in the first 6 months then every 2-3 months in case of difficulties to perform the monthly monitoring required. The patients who do not have access to regular monitoring of blood count and BCR$\mathrm{ABL}$ transcripts are advised to postpone TFR and restart TKI treatment (22).

\section{Accelerated Phase and Blast Crisis}

Patients with accelerated phase CML responding well to TKI therapy should continue with proper monitoring.

Younger patients with blast crisis may be considered for intensive TKI based therapy in centers allowing for proper monitoring and support.

\section{Allogeneic Hematopoietic Stem Cell Transplantation}

Efforts should be made not to delay admission for allogeneic transplant if indicated. Cryopreservation of donor cells prior to the procedure is preferable.

\section{Myeloproliferative Neoplasms}

Elderly patients with a Myeloproliferative Neoplasm (MPN), particularly with additional illness such as cardiovascular or thrombotic disorders and diabetes are considered more vulnerable and less able to recover from SARS-Cov-2 infection.

Table 4 summarized the recommendations for MPNs. 
TABLE 3 | Chronic myelogenous leukemia.

\begin{tabular}{ll}
\hline Testing & - For newly diagnosed patients \\
& - If fever and/or other symptoms related to SARS- \\
& Cov2 infection \\
& - Donor and recipient before allogeneic transplant \\
& - No delay \\
- No change in TKls monitoring & - No delay in changing TKls \\
Resistance/Intolerance to & - No change in monitoring \\
TKI & - If started, possible reduction in monitoring \\
Treatment-free-remission & schedules (every 1.5 months the first 6 months, \\
& then every 2-3 months. \\
& - If no possibility to perform PCR adequately, \\
& postponed TFR and restart TKI \\
Accelerated phase & - No change if response to TKls \\
Blast crisis & - Intensive TKI-based therapy \\
Allogeneic transplant & No delay \\
\hline
\end{tabular}

TABLE 4 | Myeloproliferative neoplasms.

\begin{tabular}{ll}
\hline Testing & - For newly diagnosed patients \\
- If fever and/or other symptoms related to SARS-Cov2 & infection \\
- Donor and recipient before allogeneic transplant \\
- PV: Phlebotomy and Aspirin \\
Initial therapy \\
- ET: No adjustment of cytoreductive therapy \\
- PMF: ruxolitinib for intermediate or higher risk patients. \\
Monitoring of blood count and coagulation \\
parameters (risk of bleeding or thrombosis) \\
Allogeneic transplant \\
for PMF
\end{tabular}

\section{Testing for SARS-Cov-2}

Testing should be performed for all newly diagnosed MPNs patients, and if fever and/or other symptoms related to SARSCov-2. Donor and recipient for allogeneic transplant should also be tested before starting the procedure.

\section{Treatments}

There is currently no evidence that elderly patients, with essential thrombocythemia (ET) or polycythemia vera (PV) who are on anticoagulants are at increased risk of SARSCov-2 infection compared with the general population. Some treatments for MPNs or co-morbid cardio vascular thrombotic or cardiovascular disorders may decrease the ability to recover from SARS-Cov-2 infection. Patients with intermediate-2 or high-risk primary myelofibrosis (PMF) on JAK2 inhibitors could have a worse outcome if they become infected with the virus; however, the effect of JAK inhibitors increasing of SARS-Cov-2 infection is unknown (23). On the other hand, the abrupt cessation of JAK2 inhibitor (ruxolitinib) may result in progressive disease or rarely cytokine storm which worsens the clinical course of SARS-Cov2 infection, and it has been suggested that ruxolitinib it can be a possible therapy for cytokines storm in critically ill COVID-19 patients (24). Given the base line increased risk and frequenting of thromboembolic complications in MPNs and advanced stage
COVID-19 patients, it is necessary to reduce hematocrit $<45 \%$. And to maintain a WBC $<10 \times 10^{9} / \mathrm{L}$ and platelet $<400 \times 10^{9} / \mathrm{L}$. Cytoreductive therapy should be maintain if there is a history or an active thromboembolic or hemorrhagic event (25).

Patients on phlebotomy for PV can maintain it but decreasing the frequency is considered. Because of unclear situation with MPNs, cytoreduction (hydroxyurea, IFN, anagrelide....) should not be adjusted. For PMF patients the management must be established according to know prognostic factors which can be evaluated by MIPSS or DIPSS plus or equivalent (26). JAK2 inhibitors therapy such as ruxolitinib could be given if clinical situation allows. If ruxolitinib needs to be stopped, careful tapering must be done (25).

\section{Allogeneic Hematopoietic Stem Cell Transplantation for PMF}

Efforts should be made not to delay admission for allogeneic transplant. Cryopreservation of donor cells prior to the procedure is preferable.

\section{MYELOID HEMATOLOGICAL MALIGNANCIES WITH SARS-Cov-2 INFECTION (PCR POSITIVE AND/OR SYMPTOMS)}

Following the recent update in the management of SARSCov-2 infection, several consideration were taken into account $(4-8,27)$.

\section{Acute Myeloblastic Leukemia}

In young adults positive for SARS-Cov-2 but asymptomatic, standard induction chemotherapy with $3+7$ or similar regimen can be given. For patients positive and symptomatic, induction therapy is postponed if the disease is low proliferative until negativation of PCR and symptoms. Awaiting, HU and hypomethylating agents with or without venetoclax can be given.

For patient in complete remission and positive for SARSCov-2, consolidation chemotherapy should be postponed until PCR negativity and/or resolution of symptoms. Awaiting, hypomethylating agents can be given.

Other targeted therapy (Anti-FLT3 and IDH1/2), if indicated, could be administered.

Drug interaction due to CYP3 inhibitors or potential QT prolongation between anti FLT-3, venetoclax and current therapeutic options of SARS-Cov-2 infection must be carefully taken into consideration.

Allogeneic transplant must be deferred until no symptoms and PCR negativity for at least 3-4 weeks.

\section{Myelodysplastic Syndromes}

There is no change in specific therapy for infected patients.

Drug interaction due to CYP3 inhibitors or potential QT prolongation between specific treatment and current therapeutic options of SARS-Cov-2 infection must be carefully taken into consideration. 
Allogeneic transplant must be deferred until no symptoms and PCR negativity for at least 3-4 weeks.

\section{Chronic Myelogenous Leukemia}

If case of non-severe infection, interruption of TKIs therapy is not recommended except if the patient has cardio pulmonary toxicity due to TKIs.

TKIs are interrupted in case of severe infection.

Patient in TFR should be managed the same way as the general population.

Allogeneic transplant should be deferred until no symptoms and PCR negativity for at least 3-4 weeks.

\section{Myeloproliferative Neoplasms}

The patients should be started or switched to heparin prophylactically. In case of massive or sub-massive pulmonary embolism which should be suspected in case of respiratory deterioration and a sudden increase of D-Dimer, thrombolysis should be considered.

Cytoreductive therapy (HU, IFN, anagrelide) should not be stopped or empirically adjusted.

Dose of ruxolitinib should be modified if an antiviral therapy (lopinavir, ritonavir) is used for SARS-Cov-2 infection.

Careful monitoring of blood counts and coagulation parameters, in particular with anticoagulation to intercept thrombocytopenia or coagulation abnormalities, must be done because of high risk of thrombosis and bleeding.

Allogeneic transplant should be deferred until resolution of symptoms and PCR negativity for at least 3-4 weeks.

\section{RECOMMENDATIONS TO REDUCE SARS-Cov-2 INFECTION IN LYMPHOID HEMATOLOGICAL MALIGNANCIES}

\section{Acute Lymphoblastic Leukemia}

Table 5 summarizes the recommendations for Acute Lymphoblastic Leukemia (ALL).

\section{Testing for SARS-Cov-2}

Testing is recommended at diagnosis and at initiation of every cycle of therapy. It should be done if fever and/or other symptoms related to SARS-Cov-2 infection at any time. Donor and recipient are tested before allogeneic transplantation.

\section{Induction Therapy}

For the patients with ALL Ph-negative, standard induction therapy can be done because delay is associated with poor outcome; however, lower doses of steroids should be given. Reduction of anthracyclines doses is preferred in the patients at high-risk complications if SARS-CoV-2 is contracted. Because of the changes in coagulation parameters and thromboembolic complications induced by the virus, reduction of the dose of asparaginase is recommended. Anti CD20, if indicated, could be skipped; however, if IgG level is adequate and no infection, it administration is considered.

Because of the good results of anti CD22 (inotuzumab ozogamycin), in combination with low-intensity chemotherapy [e.g., minihyperCVD (cyclophosphamide, vincristine, dexamethasone)] for older patients with ALL Ph-negative in first line therapy, this approach could be considered as an alternative, but it depends on the availability and the cost of anti CD22. Blinatumomab, a specific antibody anti-CD3/CD19, based combination could be also considered $(28,29)$.

For the patients with ALL $\mathrm{Ph}$ positive, using tyrosine kinase inhibitors (TKIs) with steroids and vincristine instead of multiagent chemotherapy should be considered (30).

G-CSF should be given to shorten neutropenia.

\section{Post-remission Therapy}

Delay of intensification course is preferable, however, if started, some modifications of intensive post-remission therapy should be done to reduce hospital admissions and/or prolonged immunosuppression and neutropenia. For example, cytarabine could be given s/c at home, and anti CD20 given only if IgG level is normal.

Maintenance therapy can be given on schedule but with a reduction in steroid doses, and absolute neutrophil count (ANC) should be maintained at $\geq 1 \times 10^{9} \mathrm{~L}$.

G-CSF should be given to shorten neutropenia.

\section{Relapse/Refractory ALL}

For patients with B-ALL, specific antibodies (inotuzumab or blinatumomab) are preferable to other regimens (28).

For patients with T-ALL, salvage regimens according to standard regimens but with possible doses reduction can be given (28).

\section{Allogeneic Hematopoietic Stem Cell Transplantation} For patients with high-risk ALL, allogeneic transplant can be performed in first remission, but taking into account the risks/benefits. Patients who achieve a second complete remission should undergo allogeneic transplant despite pandemic. Cryopreservation of donor cells before starting the procedure should be considered.

\section{Chronic Lymphocytic Leukemia}

Table 6 summarizes the recommendations for Chronic Lymphocytic Leukemia (CLL).

\section{Introduction}

Patients with CLL are at higher risk of contraction of severe SARS-Cov-2 infection than general population because of underlying immunodeficiency and inadequate immune response to infection.

\section{Testing for SARS-Cov-2}

Testing should be performed for all newly diagnosed patients and if fever and/or other symptoms related to SARS-Cov-2 infection at any time. Donor and recipient should be tested before starting allogeneic transplantation.

\section{Treatment}

For newly diagnosed patients, if immediate therapy is required, treatment with monoclonal antibodies (anti CD20) should be avoided or skipped. BCR signaling inhibitors can be given, 
TABLE 5 | Acute lymphoblastic leukemia.

\begin{tabular}{|c|c|}
\hline Testing & $\begin{array}{l}\text { - At diagnosis } \\
\text { - Before every cycle } \\
\text { - If fever and/or other symptoms related to SARS-Cov-2 } \\
\text { infection } \\
\text { - Donor and recipient before allogeneic transplantation }\end{array}$ \\
\hline Induction & $\begin{array}{l}\text { - Ph negative } \\
\circ \text { Can be done according to standard regimens } \\
\text { but lower doses of steroids, lower doses of } \\
\text { anthracyclines if and lower doses of asparaginase } \\
\circ \text { No anti CD2O if lgG is low } \\
\circ \text { Light chemotherapy and antibodies (inotuzumab, } \\
\text { blinatumomab) } \\
\text { - Ph positive } \\
\text { Consider Tyrosine Kinase Inhibitors (TKis) and } \\
\text { steroids with light chemotherapy (vincristine) } \\
\text { without multiagent chemotherapy } \\
\text { - G-CSF to shorten neutropenia }\end{array}$ \\
\hline $\begin{array}{l}\text { Intensification } \\
\text { post-remission }\end{array}$ & $\begin{array}{l}\text { - Modifications to reduce admissions and prolonged } \\
\text { neutropenia }\end{array}$ \\
\hline Maintenance therapy & $\begin{array}{l}\text { - On schedule, but lower doses of steroids (maintain } \\
\text { ANC } \geq 1 \times 10^{9} / \mathrm{L} \text { ) }\end{array}$ \\
\hline Relapsed/refractory & $\begin{array}{l}\text { - B-ALL: antibodies (inotuzumab, blinatunomab) } \\
\text { preferred to multiagent chemotherapy } \\
\text { - T-ALL: according to standard regimens but dose } \\
\text { reduction }\end{array}$ \\
\hline $\begin{array}{l}\text { Allogeneic } \\
\text { transplantation }\end{array}$ & - No delay \\
\hline
\end{tabular}

TABLE 6 | Chronic lymphocytic leukemia.

\begin{tabular}{ll}
\hline Testing & - At diagnosis \\
& - If fever and/or other symptoms related to SARS-CoV-2 \\
- Donor and recipient before allogeneic transplantation & - If immediate therapy is required, avoid monoclonal \\
Newly diagnosis & antibodies (anti CD20) and anti Bcl 2 (Venetoclax) \\
& - IVIG should be given for patients with \\
& hypogammaglobulinemia and recurrent infections, but less \\
& frequently (every 6-8 weeks) \\
& - Skip or delay monoclonal antibodies \\
On therapy & IVIG should be given for patients with \\
& hypogammaglobulinemia and recurrent infection, but less \\
& frequently (6-8 weeks) \\
Allogeneic & Delay if stable disease \\
transplantation &
\end{tabular}

but treatment with anti Bcl-2 (venetoclax), which requires at its initiation multiple visits and lab tests, should be delayed or avoided.

Immunoglobulins (IVIG) should be given for patients with hypogammaglobulinemia and severe or recurrent infections, but infusion of IVIG could be done less frequently (every 6-8 weeks).

For the patients already on therapy, no significant changes are required except for monoclonal antibodies (anti CD20) and for IVIG, which must be similar to newly diagnosed patients (31).

\section{Hematopoietic Stem Cell Transplantation}

Delaying allogeneic transplantation should be considered if the disease is stable. Cryopreservation of donor cells should be considered before starting the procedure.

\section{Aggressive Lymphomas Diffuse Large B-Cell Lymphoma}

Table 7 summarizes the recommendations for Diffuse Large BCell Lymphoma (DLBCL).

\section{Testing for SARS-Cov-2}

Testing should be performed for all newly diagnosed patients, and at the start of treatment cycle. Patients with fever and/or other symptoms related to SARS-Cov-2 infection should have an additional test at any time. All patients should be tested before mobilization of peripheral blood stem cells and before autologous transplantation. Donor and recipient for allogeneic transplant should also be tested before the procedure.

\section{Initial Therapy}

For younger patients R-CHOP (rituximab, cyclophosphamide, doxorubicin hydrochloride, vincristine, and prednisone) every 3 weeks is the preferable regimen; however, intensive but more toxic therapy such as DA-EPOCH-R (etoposide, prednisone, vincristine, cyclophosphamide, doxorubicin, rituximab) or $\mathrm{R}$ ACVBP (doxorubicin, cyclophosphamide, vindesine, bleomycin, prednisone, and rituximab) for high-risk or double hit could be administered if the center has the capacity to deliver it. In this case, patients should receive G-CSF to minimize neutropenia (32).

If there is a CNS involvement, high-dose methotrexate (for example 2 cycles) and intrathecal chemotherapy can be given.

For older patients, R-mini CHOP with G-CSF is recommended (32).

\section{Relapse/Refractory DLBCL}

Salvage therapy according to standard regimens could be given with close follow-up and administration of G-CSF to minimize neutropenia. Anti CD79 antibody (polatuzumab) in combination with anti CD20 and chemotherapy can also be administered (33). T-cell suppressive agents (example bendamustine) should be avoided. If the center cannot handle these salvage regimens, outpatient therapy including oral targeted therapy (e.g., lenalidomide) with anti CD20 is an alternative (34).

\section{Hematopoietic Stem Cell Transplantation}

Autologous peripheral blood stem cells transplantation, mainly indicated in sensitive relapse, can be performed.

Allogeneic hematopoietic stem cells transplantation can be delayed if stable disease. Cryopreservation of donor cells should be considered before starting the procedure.

\section{Mantle Cell Lymphoma}

For fit patients, first line therapy according to standard protocols including anti-CD20 may be given with dose reduction.

For elderly patients, R-CHOP, or R-mini CHOP should be used.

Local radiotherapy and steroids for symptomatic localized disease should be considered.

Systemic therapy for relapsed/refractory disease may be reduced in intensity or replaced by oral targeted based regimens (lenalidomide, BCR inhibitors like ibrutinib) (35). 
TABLE 7 | Diffuse Large B-cell NHL.

\begin{tabular}{|c|c|}
\hline Testing & $\begin{array}{l}\text { - At diagnosis } \\
\text { - Before every cycle } \\
\text { - If fever and/or other symptoms related to SARS-Cov-2 } \\
\text { infection } \\
\text { - Before mobilization and before autologous transplantation } \\
\text { - Donor and recipient before allogeneic transplantation }\end{array}$ \\
\hline Initial therapy & $\begin{array}{l}\text { - Younger patients: } \\
\circ \text { R-CHOP } \\
\circ \text { CNS prophylaxis to high-risk groups (testicular, renal, } \\
\text { adrenal) } \\
\circ \text { CNS involvement: intrathecal chemotherapy/hig- } \\
\text { dose methotrexate } \\
\circ \text { More intensive }\{[\mathrm{DA}-\mathrm{EPOCH}-\mathrm{R} \text { (rituximab, etoposide } \\
\text { phosphate, prednisone, vincristine sulfate (Oncovin), } \\
\text { cyclophosphamide, and doxorubicin hydrochloride) } \\
\text { or R-ACVBP (adriamycin, cyclophosphamide, } \\
\text { vindesine, bleomycin, prednisone, rituximab)]\} for } \\
\text { high-risk or double hit } \\
\circ \text { Delay radiotherapy } \\
\text { - Elderly patients: } \\
\circ \text { R-mini CHOP } \\
\text { - G-CSF to minimize neutropenia }\end{array}$ \\
\hline Relapse/refractory & $\begin{array}{l}\text { - Salvage therapy according to standard protocols } \\
\text { - Avoid T-cell suppressive agents (bendamustine) } \\
\text { - Consider outpatient salvage regimens (rituximab, revlimid } \\
\pm \text { anti CD-20) } \\
\text { - Anti CD796 based therapy } \\
\text { - G-CSF to minimize neutropenia }\end{array}$ \\
\hline $\begin{array}{l}\text { Hematopoietic } \\
\text { stem cells } \\
\text { transplant }\end{array}$ & $\begin{array}{l}\text { - No delay for autologous transplantation in sensitive relapse } \\
\text { - Allogeneic transplantation delayed if stable disease }\end{array}$ \\
\hline
\end{tabular}

T-cell suppressive agents (e.g., bendamustine) should be avoided.

Anti CD20 (rituximab) can be administered in first and subsequent lines; however, maintenance therapy with rituximab may be delayed.

For transplantation, strategy is similar to DLBCL.

G-CSF support to minimize neutropenia should be used.

\section{Primary Mediastinal B-Cell Lymphoma}

$\mathrm{R}-\mathrm{CHOP}-14$ and omitting radiotherapy if PET negative should be considered.

More aggressive chemotherapy (e.g., DA-EPOCH-R) with omission of radiotherapy if PET negative should be considered for selected patients (36).

For relapse/refractory and transplant, the strategy is similar to DLBCL.

\section{Burkitt's Lymphoma}

First line therapy according to standard protocols can be given with a consideration to reduce methotrexate and cytarabine doses (37).

\section{Primary CNS Lymphoma}

For first line therapy, reduction of the dose of cytarabine per cycle should be considered. Thiotepa should be omitted for elderly patients (38).
For autologous transplant as consolidation therapy, reduction of the doses of thiotepa should be done.

\section{Peripheral T-Cell Lymphoma}

For first line therapy, CHOP with G-CSG support can be given; however, standard protocols can also be given if the center can handle them.

Autologous transplant as consolidation can be delayed if stable disease, otherwise for autologous and allogeneic transplant, the strategy is similar to DLBCL.

For relapse/refractory patients, management can be decided on case-by-case. If indicated, anti CD30 (brentuximab vedotin) combination can be given (39).

\section{Cutaneous T-Cell Lymphoma}

Patients with primary cutaneous lymphoma (PCL) tend to be older and remain on long-term immunosuppressive therapy for disease control which can contribute to the development of more severe complications for SARS-Cov-2 infection.

For low-risk PCL patients, local therapies that can be utilized at home should be continued (e.g., topical retinoids, topical steroids, home UVB heliotherapy). Electron beam radiation therapy and ultraviolet light therapy should be delayed.

For intermediate-risk patients, treatment with oral retinoids, oral methotrexate, oral steroids, interferon (IFN), vorinostat may be continued with dose adjustment which allows limiting hospital visits and lab monitoring.

For high-risk patients, infusion regimens (parotrexate, romidepsin, brentuximab vedotin, gemcitabine, etc.) may be adjusted with increase to treatment intervals, particularly for romidepsin.

Other infusion regimens (CHOP, alemtuzumab, fludarabine) which can lead to significant cytopenia, should not be administered (40).

Allogeneic hematopoietic stem cells transplantation should be delayed during the pandemic.

\section{Indolent Lymphoma}

Table 8 summarizes the recommendations for indolent lymphoma.

\section{Testing for SARS-Cov-2}

Testing should be performed for all newly diagnosed patient and if fever and/or other symptoms related to SARS-Cov2 infection at any time. All patients should be tested before mobilization of peripheral blood stem cells and before autologous transplantation. Donor and recipient should be tested before starting allogeneic transplantation.

\section{Newly Diagnosed Patients}

If immediate treatment is required, radiotherapy could be an option for limited disease. Anti CD20 monotherapy could be administered; however if a combination of anti CD20 with chemotherapy should be given, anti CD20-CVP (cyclophosphamide, vincristine, prednisone) or anti CD20$\mathrm{CHOP}$, are preferred to anti CD20-bendamustine because of the immunosuppressive properties of bendamustine. 
TABLE 8 | Indolent lymphoma.

\begin{tabular}{|c|c|}
\hline Testing & $\begin{array}{l}\text { - At diagnosis } \\
\text { - If fever and/or other symptoms related to SARS-Cov-2 } \\
\text { infection } \\
\text { - Before mobilization and before autologous } \\
\text { transplantation } \\
\text { - Donor and recipient before allogeneic transplantation }\end{array}$ \\
\hline Initial therapy & $\begin{array}{l}\text { - Radiotherapy for limited disease } \\
\text { - Anti CD20 } \\
\text { - Anti CD20-CVP (cyclophosphamide, vincristine, } \\
\text { prednisolone) or anti CD20-CHOP (cyclophosphamide, } \\
\text { doxorubicin hydrochloride, vincristine, prednisone) } \\
\text { preferred to anti CD20-bendamustine } \\
\text { - For small lymphocytic lymphoma/marginal zone/mantle } \\
\text { cell, give oral targeted therapy (e.g., ibrutinib } \pm \text { anti } \\
\text { CD-20) } \\
\text { - G-CSF to shorten neutropenia } \\
\text { - IVIG for patients with low lgG levels and recurrent } \\
\text { infections }\end{array}$ \\
\hline $\begin{array}{l}\text { Maintenance } \\
\text { therapy }\end{array}$ & $\begin{array}{l}\text { - Anti CD20 should not be initiated or should be stopped } \\
\text { in elderly or younger patients with low lgG levels }\end{array}$ \\
\hline Transformation & - Treatment similar to aggressive lymphoma \\
\hline Relapsed/refractory & $\begin{array}{l}\text { - Oral targeted therapy (ibrutinib, lenalidomide) with anti } \\
\text { CD20 are preferred to more intensive therapy } \\
\text { - No bendamustine based combinations }\end{array}$ \\
\hline $\begin{array}{l}\text { Hematopoietic stem } \\
\text { cells transplantation }\end{array}$ & $\begin{array}{l}\text { - Autologous or Allogeneic transplantation should not be } \\
\text { delayed for the patients with transformation, and delayed } \\
\text { for other patients with stable disease after relapse }\end{array}$ \\
\hline
\end{tabular}

Maintenance therapy with anti CD20 should be stopped or not initiated until end of SARS-COV-2 pandemic in older patients and in younger patients with low immunoglobulin levels (IgG).

For small lymphocytic lymphoma (SLL), marginal zone lymphoma or mantle cell lymphoma, specific oral targeted therapy could be given (e.g., ibrutinib) replacing intravenous treatment.

For patients who have started treatment and are in response, reducing the number of cycles and replacing the remaining cycles by oral less immunosuppressive therapy should be considered. If the patient on maintenance therapy is elderly or younger with low immunoglobulin levels (IgG), maintenance therapy should be stopped.

G-CSF support is recommended for neutropenic patients, particularly in case of recurrent infections, and IVIG supplementation could be given in patients with low IgG levels (41).

\section{Transformation}

In case of the transformation of the indolent lymphoma, treatment will follow the algorithm of aggressive lymphoma with intensive chemo-immunotherapy. Oral agents such as ibrutinib or lenalidomide with or without anti CD20 can also be considered as an alternative if the usage of intensive therapy is not possible (41).

\section{Relapsed/Refractory Patients}

Patients are managed on case-by-case basis (42).

\section{Hematopoietic Stem Cell Transplantation}

Autologous or allogeneic hematopoietic stem cell transplantation should be performed for the patient in transformation of the indolent lymphoma, but can be delayed for the other patients with a stable disease. Cryopreservation of donor cells should be considered before starting allogeneic transplantation.

\section{Hodgkin's Lymphoma}

Table 9 summarizes the recommendations for Hodgkin's Lymphoma (HL).

The objective for HL is to reduce patients' exposure to the hospital setting due to radiotherapy, to reduce or avoid usage of bleomycin which induces lung toxicity which is becoming problematic during this pandemic, and to delay if possible intensive chemotherapy which needs recurrent hospital admissions and induces hematological toxicities.

\section{Testing for SARS-Cov-2}

Testing should be performed for all newly diagnosed patients, then at the start of the next treatment cycle. Patients with fever and/or other symptoms related to SARS-Cov-2 infection should have an additional test at any time. All patients should be tested before mobilization of peripheral blood stem cells and before autologous transplantation. Donor and recipient for allogeneic transplant should also be tested before starting the procedure.

\section{First Line Therapy}

For patients with favorable early stage disease, two cycles of ABVD and limited radiotherapy remains an option, but a modified approach of radiotherapy reducing hospital attendances can be considered. However, an alternative to removal of radiotherapy could be four cycles of ABVD. Interim PET 2 can be maintained. If the PET 2 is negative and ABVD continued, consider omitting bleomycin for the next two cycles should be done $(43,44)$.

For patients with unfavorable early stage disease, four cycles of ABVD followed by radiotherapy remain an option with modifying the schedule of radiotherapy to limit patients exposure to the hospital. However, an alternative to removal of radiotherapy is to give ABVD until six cycles if interim PET 2 scan shows optional response. Omission of bleomycin after a negative PET 2 is recommended.

For patients with advanced stage disease, six cycles of ABVD with an interim PET 2 evaluation remains an option (44) and bleomycin is to be omitted in the following cycles after a negative PET 2, based on the results of RATHL study (risk-adapted therapy for $\mathrm{HL}$ ) which showed no difference in 3 years progression-free survival (PFS) between 2 cycles of ABVD (45), followed by 4 cycles of AVD and 6 cycles of ABVD. It is also possible to consider A+AVD (brentuximab bedotin, doxorubicin, vinblastine, dacarbazine) regimen omitting bleomycin and introducing adcetris (anti CD30-brentuximab vedotin) based on the results of ECHELON-1 study which demonstrated that brentuximab vedotin (A) with AVD exhibited superior modified PFS vs. ABVD for frontline treatment for patients with stage III/IV classical HL (46), and because of the approval in Lebanon of A + AVD for first line therapy for 
TABLE 9 | Hodgkin lymphoma.

\begin{tabular}{|c|c|}
\hline st & $\begin{array}{l}\text { - Before every cycle } \\
\text { - If fever and/or other symptoms related to SARS-Cov-2 } \\
\text { infection } \\
\text { - Before mobilization and before autologous } \\
\text { transplantation } \\
\text { - Donor and recipient before allogeneic transplantation }\end{array}$ \\
\hline $\begin{array}{l}\text { - Younger patients } \\
\text { - Early favorable }\end{array}$ & $\begin{array}{l}\text { - ABVD (adriamycin, bleomycin, vinblastine, dacarbazine) } \\
\times 2 \text { and modified radiotherapy schedule } \\
\text { - } \text { ABVD } \times 4 \text { (no bleomycin for cycles } 3,4 \text { ) } \\
\text { - G-CSF to shorten neutropenia and prophylactic } \\
\text { antibiotics }\end{array}$ \\
\hline $\begin{array}{l}\text { - Younger patients } \\
\text { - Early unfavorable }\end{array}$ & $\begin{array}{l}\text { - } A B V D \times 4 \text { and modified radiotherapy schedule } \\
\text { - } A B V D \times 6 \text { (no bleomycin starting cycle } 3 \text { ) } \\
\text { - G-CSF to shorten neutropenia and prophylactic } \\
\text { antibiotics }\end{array}$ \\
\hline $\begin{array}{l}\text { - Younger patients } \\
\text { - Advanced }\end{array}$ & $\begin{array}{l}\text { - } \text { ABVD } \times 6 \text { (no bleomycin starting cycle } 3 \text { ) } \\
\text { - AAVD (brentuximab vedotin, doxorubicin, vinblastine, } \\
\text { dacarbazine) (ECHELON 1) } \\
\text { - RATHL approach but for escalation after ABVD } \\
\text { with lower steroid doses BEACOPP (bleomycin, } \\
\text { etoposide, adriamycin, cyclophosphamide, vincristine, } \\
\text { procarbazine, prednisone) } \\
\text { - G-CSF to shorten neutropenia and prophylactic } \\
\text { antibiotic }\end{array}$ \\
\hline Rela & $\begin{array}{l}\text { - Outpatient salvage therapy (gemcitabine based, } \\
\text { brentuximab vedotin, Anti PD1/PDL1) preferred to } \\
\text { multiagent chemotherapy }\end{array}$ \\
\hline $\begin{array}{l}\text { Nodular lymphocyte } \\
\text { predominant } \\
\text { Hodgkin }\end{array}$ & $\begin{array}{l}\text { - Radiotherapy for symptomatic sites } \\
\text { - Single agent anti CD20 } \\
\text { - If systemic therapy: R-CVP (cyclophosphamide, } \\
\text { vincristine, prednisone) }\end{array}$ \\
\hline $\begin{array}{l}\mathrm{He} \\
\mathrm{ce}\end{array}$ & $\begin{array}{l}\text { - No delay for Autologous transplantation in sensitive } \\
\text { relapse } \\
\text { - Allogeneic transplantation delayed if stable disease }\end{array}$ \\
\hline
\end{tabular}

stage IV HL. Do note that this approach is PET 2 independent; however, more expensive and needs G-CSF prophylactically to prevent at maximum febrile neutropenia without forgetting peripheral neuropathy induced by A + AVD.

In case of positive interim PET 2 scan, treatment intensification can be done as offered in RATHL, GITIL/FIL HD 0607 (47) and SWOG s0816 studies (48); however, four cycles of BEACOPP (bleomycin, etoposide, doxorubicin, cyclophosphamide, vincristine, procarbazine and prednisolone) should be considered instead of BEACOPP escalated.

For patients with nodular lymphocyte predominant HL, radiotherapy on symptomatic sites can be done. Single agent anti CD-20 can also be given. If systematic therapy is to be given, R-CVP should be used (43).

\section{Relapse/Refractory HL}

Outpatient salvage regimens are preferred to regimens that require recurrent and longer hospitalization, for example gemcitabine-based or brentuximab vedotin or anti PD1/PDL1 (nivolumab, pembrolizumab) (49).

\section{Elderly Patients}

All elderly patients ( $>60 \mathrm{yo}$ ) can receive treatment according to standard regimens but at reduced doses. Bleomycin should be omitted from therapy.

\section{Supportive Care}

G-CSF can be given 3-5 days at mid cycle of chemotherapy to reduce severe neutropenia. Prophylactic antibiotherapy for expected neutropenic patients could be given.

\section{Hematopoietic Stem Cell Transplantation}

Autologous peripheral blood stem cell transplantation usually used as consolidation after salvage therapy can be performed.

Allogeneic stem cell transplantation which is not commonly used in HL and usually indicated for relapse after autologous transplant, can be delayed if stable disease. Cryopreservation of donor cells should be considered before starting the procedure.

\section{Multiple Myeloma}

Table 10 summarizes the recommendations for Multiple Myeloma (MM).

\section{Introduction}

Because of both humoral and cellular immunity [B, T, dendritic and natural killer (NK) cells] are impaired in MM, patients with this disease are able to easily contract SARS-Cov-2 infection and develop severe complications. Moreover, the current drugs against MM includes agents with significant hematological toxicity. Patients under treatment with immunomodulatory drugs (IMiDs) and proteasome inhibitors (PIs) are at increased risk of severe infection because of T-cell function impairment induced by these drugs. Although, anti-CD38 antibodies (daratunumab) reduce immunosuppressive regulatory $\mathrm{T}$ cells and deplete NK cells. Furthermore, patients with MM are older adults with possible several co-morbidities and increased risk for venous thromboembolism (33).

\section{Testing for SARS-Cov-2}

Testing should be performed for all newly diagnosed patients and if fever and/or other symptoms related to SARS-CoV2 infection at any time. All patients should be tested before mobilization of peripheral blood stem cells and before autologous transplantation. Donor and recipient for allogeneic transplant should also be tested before the procedure.

\section{Newly Diagnosed Patients}

Specific treatment should be delayed for patients with smoldering MM or without CRAB symptoms (elevated calcium, renal failure, anemia, bone lesions), or with monoclonal gammopathy of undetermined significance (MGUS).

Patients fulfilling the CRAB criteria and/or symptoms related to multiple myeloma should be offered an initial therapy; however, treatment should be individualized to limit possible exposure to SARS-CoV-2.

For transplant-eligible patients, triplet therapy can be administered, example VRd (bortezomib, lenalidomide, dexamethasone), VCD (bortezomib, cyclophosphamide, dexamethasone), VTD (bortezomib, thalidomide, and 
TABLE 10 | Multiple myeloma.

\begin{tabular}{|c|c|}
\hline Testing & $\begin{array}{l}\text { - At diagnosis } \\
\text { - If fever and/or other symptoms related to SARS-CoV-2 } \\
\text { - Before mobilization and before autologous } \\
\text { transplantation }\end{array}$ \\
\hline Initial therapy & $\begin{array}{l}\text { - No for patients without CRAB or smoldering MM or } \\
\text { MGUS } \\
\text { - If immediate therapy indicated for transplant } \\
\text { eligible: } \\
\text { Triplet therapy [VRd (revlimid, velcade, } \\
\text { dexamethasone) preferred to VTD (velcade, } \\
\text { thalidomide, dexamethasone) or VCD (bortezomib, } \\
\text { cyclophosphamide, dexamethasone)], but } \\
\text { bortezomib weekly and lower doses of steroids. } \\
\text { Possible usage of combined oral therapy (ixazomib } \\
\text { or revlimid based) } \\
\text { Prolongation of therapy to 6-8 cycles followed } \\
\text { by oral doublet if response to delay autologous } \\
\text { transplantation } \\
\text { - If immediate therapy indicated for transplant } \\
\text { ineligible: } \\
\text { Triplet }\{[\text { light VRD, DRd (daratumumab + revlimid } \\
+ \text { dexamethasone), ixazomib Rd]\} or doublet (Rd) } \\
\text { with dose reduction of steroids, depending on risk } \\
\text { and co-morbidities }\end{array}$ \\
\hline $\begin{array}{l}\text { Autologous } \\
\text { peripheral blood stem } \\
\text { cell transplantation }\end{array}$ & $\begin{array}{l}\text { - Delay is preferred } \\
\text { - Peripheral Blood Stem Cells mobilization with G-CSF } \\
\text { alone }\end{array}$ \\
\hline Maintenance therapy & - Lenalidomide monotherapy preferred \\
\hline Relapsed/refractory & $\begin{array}{l}\text { - Delay of treatment if biochemical relapse } \\
\text { - Treatment according to standard regimens but } \\
\text { consider using s/c and/or oral combinations }\end{array}$ \\
\hline
\end{tabular}

dexamethasone); however, bortezomib doses is reduced to one weekly administration, and steroids at half-regimen doses or lower. Subcutaneous administration at home of bortezomib is preferred to limit hospital admissions. Oral triplet regimen could be used as an alternative (e.g., ixazomib, lenalidomide, dexamethazone). If stem cell transplant is differed, first line therapy could be prolonged to 6-8 cycles; then, patients could be continued on oral regimen consolidation during the SARS$\mathrm{CoV}-2$ pandemic, especially those with stable disease and with standard cytogenetic risk. Maintenance therapy can be done with lenalidomide alone (50-52).

For transplant ineligible patients, regimens like $\mathrm{Rd}$ (lenalidomide and dexamethasone) and DRd (daratunumab, lenalidomide and dexamethasone) could be administered depending on cytogenetic risk and comorbidities; however, doses of daratumumab should be given at a less intensive schedule. For these patients de-escalating steroids after six cycles should be considered. Oral regimens particularly ixazomib based can be given $(50,53,54)$.

\section{Relapse/Refractory Patients}

For patients with biochemical relapse, deferment of treatment should be done.

For the remaining patients, other lines of therapy should be initiated as per standard regimens considering using s/c and oral combinations to reduce hospital attendances. Daratunumab based regimens can be administered at a less intensive schedules $(50,55,56)$.

\section{Hematopoietic Stem Cell Transplantation}

For transplant eligible patients, delaying the stem cell transplant is considered; however peripheral stem cell collection and cryopreservation awaiting autologous transplantation could be performed after mobilization with G-CSF alone.

\section{Supportive Care}

Patients with a history of neutropenia and/or recurrent infections should receive G-CSF prophylactically.

Vaccination against influenza and pneumococcal species is highly recommended. Co-trimoxazole prophylaxis for pneumocystis jirovecii, antibiotics and antiherpetic prophylaxis are highly recommended.

Erythropoiesis stimulating agents should be given for severe anemia not responding to treatment. Low-molecular-weight heparin could be considered over aspirin as thromboprophlaxis.

Interval of administration of zolidronic acid should be prolonged to 3 months for all patients to limit hospital admissions.

Denosumab, when available, may be administered at home but must educate for self-administration if there is not a nursing facility.

\section{LYMPHOID HEMATOLOGICAL MALIGNANCIES WITH SARS-Cov-2 INFECTION (PCR POSITIVE AND/OR SYMPTOMS)}

\section{Acute Lymphoblastic Leukemia}

Systemic therapy should be delayed until resolution of the symptoms and/or PCR negativity.

Intrathecal chemotherapy can be given.

Tyrosine Kinase inhibitors can be given.

Allogeneic transplant should be deferred until resolution of symptoms and PCR negativity for at least 3-4 weeks.

A careful attention should be taken for leukemia drugs interaction with the current therapeutic options of SARS-Cov2 infection such as drugs inducing QT prolongation, and antivirals (lopinavir/ritonavir) which can increase methotrexate and vincristine concentration.

\section{Chronic Lymphocytic Leukemia}

For patients with no or mild symptoms, the approach is similar to those without SARS-Cov-2 infection.

For patients with more severe symptoms, monoclonal antibodies (e.g., anti CD-20) should not be used or hold if previously started.

BCR signaling inhibitors can be given.

IVIG can be given, but assessment of risks vs. benefits and close monitoring are necessary because of the higher risk of thromboembolic events with SARS-Cov-2 infection.

Allogeneic transplant should be deferred until resolution of symptoms and PCR negativity for at least 3-4 weeks. 
A careful attention should be taken for drugs interaction between venetoclax and some current therapeutic options for SARS-Cov-2 infection.

\section{Lymphomas}

If the patient has a non-severe SARS-Cov2 infection, it is not necessary to stop specific therapy; however, administration of anti CD-20 must be avoided.

In case of severe COVID-19, specific therapy should be delayed until recovery from the infection.

Allogeneic and autologous transplantation should be deferred until resolution of the symptoms and PCR negativity for at least 3-4 weeks.

\section{Multiple Myeloma}

Patients with no symptoms of COVID-19, but with symptoms related to MM who need immediate therapy (acute renal failure, heavy anemia, extended bone disease, etc.), should start treatment, or continue if it has been started, particularly if no optimal response is obtained. However, steroids and drugs inducing lymphopenia should be de-intensified.

\section{REFERENCES}

1. Coronavirus Disease 2019. (2020). Available online at: https://www.who.int/ emergencies/diseases/novel-coronavirus-2019.

2. COVID-19 Coronavirus Lebanon Cases. (2020). Available online at: https:// www.moph.gov.lb/maps/covid19.php.

3. moph. (2020). Available online at: http://www.moph.gov.lb.

4. Association (EHA) TEH. COVID-19 Recommendations. The European Hematology Association (EHA) (2020). Available online at: https://ehaweb. org/covid-19/covid-19-recommendations/.

5. COVID-19 Resources. (2020). Available online at: https://www.hematology. org:443/covid- 19.

6. Cancer Patient Management During the COVID-19 Pandemic. ESMO (2020). Available online at: https://www.esmo.org/guidelines/cancer-patientmanagement-during-the-covid-19-pandemic.

7. Willan J, King AJ, Hayes S, Collins GP, Peniket A. Care of haematology patients in a COVID-19 epidemic. Br J Haematol. (2020) 189:241-3. doi: $10.1111 /$ bjh. 16620

8. Dholaria B, Savani BN. How do we plan hematopoietic cell transplant and cellular therapy with the looming COVID-19 threat? Br J Haematol. (2020) 189:239-40. doi: 10.1111/bjh.16597

9. Döhner H, Estey E, Grimwade D, Amadori S, Appelbaum FR, Büchner $\mathrm{T}$, et al. Diagnosis and management of AML in adults: 2017 ELN recommendations from an international expert panel. Blood. (2017) 129:42447. doi: 10.1182/blood-2016-08-733196

10. Estey EH. Acute myeloid leukemia: 2019 update on risk-stratification and management. Am J Hematol. (2018) 93:1267-91. doi: 10.1002/ajh. 25214

11. Dombret H, Gardin C. An update of current treatments for adult acute myeloid leukemia. Blood. (2016) 127:53-61. doi: 10.1182/blood-2015-08-604520

12. DiNardo CD, Pratz K, Pullarkat V, Jonas BA, Arellano M, Becker PS, et al. Venetoclax combined with decitabine or azacitidine in treatmentnaive, elderly patients with acute myeloid leukemia. Blood. (2019) 133:7-17. doi: 10.1182/blood-2018-08-868752

13. Venetoclax for AML: Changing the Treatment Paradigm. (2020). Available online at: https://www.ncbi.nlm.nih.gov/pmc/articles/PMC6929394/.
Patients with symptoms of COVID-19 should not be treated immediately or should interrupt specific therapy until resolution of the symptoms and PCR negativity. Steroids should be tapered to zero.

Autologous and allogeneic transplantation should not be performed.

A careful attention should be taken for significant interaction between anti myeloma therapy and therapeutic options for COVID-19 such as hydroxychloroquine, azithromycin and antivirals.

\section{DATA AVAILABILITY STATEMENT}

The raw data supporting the conclusions of this article will be made available by the authors, without undue reservation.

\section{AUTHOR CONTRIBUTIONS}

AI major contributors in writing the manuscript. PN contributed in data collection. AT contributed in data collection and analysis. CK contributed in writing the manuscript and data collection. All authors contributed to the article and approved the submitted version.

14. Jonas BA, Pollyea DA. How we use venetoclax with hypomethylating agents for the treatment of newly diagnosed patients with acute myeloid leukemia. Leukemia. (2019) 33:2795-804. doi: 10.1038/s41375-019-0612-8

15. Lachowiez CA, Loghavi S, Kadia TM, Daver N, Borthakur G, Pemmaraju N, et al. Outcomes of older patients with NPM1-mutated AML: current treatments and the promise of venetoclax-based regimens. Blood Adv. (2020) 4:1311-20. doi: 10.1182/bloodadvances.2019001267

16. Egan PC, Reagan JL. The return of gemtuzumab ozogamicin: a humanized anti-CD33 monoclonal antibody-drug conjugate for the treatment of newly diagnosed acute myeloid leukemia. Onco Targets Ther. (2018) 11:8265-72. doi: 10.2147/OTT.S150807

17. Opatz S, Bamopoulos SA, Metzeler KH, Herold T, Ksienzyk B, Bräundl K, et al. The clinical mutatome of core binding factor leukemia. Leukemia. (2020) 34, 1553-62. doi: 10.1038/s41375-019-0697-0

18. Wu D, Duan C, Chen L, Chen S. Efficacy and safety of different doses of cytarabine in consolidation therapy for adult acute myeloid leukemia patients: a network meta-analysis. Sci Rep. (2017) 7:9509. doi: 10.1038/s41598-017-10368-0

19. Adès L, Thomas X, Bresler AG, Raffoux E, Spertini O, Vey N, et al. Arsenic trioxide is required in the treatment of newly diagnosed acute promyelocytic leukemia. Analysis of a randomized trial (APL 2006) by the French Belgian Swiss APL group. Haematologica. (2018) 103:2033-9. doi: 10.3324/haematol.2018.198614

20. Highlights in Myelodysplastic Syndromes from the 60th American Society of Hematology Annual Meeting: Commentary. MD Anderson Cancer Center (2020). Available online at: https://mdanderson.elsevierpure.com/ en/publications/highlights-in-myelodysplastic-syndromes-from-the-60thamerican-so.

21. Fenaux P, Platzbecker U, Mufti GJ, Garcia-Manero G, Buckstein R, Santini V, et al. Luspatercept in patients with lower-risk myelodysplastic syndromes. $N$ Engl J Med. (2020) 382:140-51. doi: 10.1056/NEJMoa1908892

22. European LeukemiaNet 2020 Recommendations for Treating Chronic Myeloid Leukemia. Leukemia (2020). Available online at: https://www.nature.com/ articles/s41375-020-0776-2.

23. Mehta P, Ciurtin C, Scully M, Levi M, Chambers RC. JAK inhibitors in COVID-19: the need for vigilance regarding increased inherent thrombotic risk. Eur Respir J. (2020) 56:2001919. doi: 10.1183/13993003.01919-2020 
24. Elli EM, Baratè C, Mendicino F, Palandri F, Palumbo GA. Mechanisms underlying the anti-inflammatory and immunosuppressive activity of ruxolitinib. Front Oncol. (2019) 9:1186. doi: 10.3389/fonc.2019.01186

25. Overcoming Treatment Challenges in Myelofibrosis and Polycythemia Vera: The Role of Ruxolitinib. Europe PMC (2020). Available online at: https:// europepmc.org/article/med/27017614.

26. NCCN Guidelines for Patients Myeloproliferative Neoplasms. Myeloproliferative Neoplasms. (2019) 70. doi: 10.6004/jnccn.2017.0157

27. Expert U.S. panel develops NIH treatment guidelines for COVID-19. Natl Inst Health. (2020) 60:2606-21.

28. Rafei H, Kantarjian HM, Jabbour EJ. Recent advances in the treatment of acute lymphoblastic leukemia. Leuk Lymphoma. (2019) 60:2606-21. doi: 10.1080/10428194.2019.1605071

29. Jabbour EJ, Sasaki K, Ravandi F, Short NJ, Garcia-Manero G, Daver $\mathrm{N}$, et al. Inotuzumab ozogamicin in combination with low-intensity chemotherapy (mini-HCVD) with or without blinatumomab versus standard intensive chemotherapy (HCVAD) as frontline therapy for older patients with Philadelphia chromosome-negative acute lymphoblastic leukemia: a propensity score analysis. Cancer. (2019) 125:2579-86. doi: $10.1002 /$ cncr.32139

30. Ravandi F. How I treat Philadelphia chromosome-positive acute lymphoblastic leukemia. Blood. (2019) 133:130-6. doi: 10.1182/blood-2018-08-832105

31. Hallek M. Chronic lymphocytic leukemia: 2020 update on diagnosis, risk stratification and treatment. Am J Hematol. (2019) 94:1266-87. doi: 10.1002/ajh.25595

32. Ruppert AS, Dixon JG, Salles G, Wall A, Cunningham D, Poeschel V, et al. International prognostic indices in diffuse large B-cell lymphoma: a comparison of IPI, R-IPI, and NCCN-IPI. Blood. (2020) 135:2041-8. doi: 10.1182/blood.2019002729

33. Morschhauser F, Flinn I, Advani RH, Sehn LH, Kolibaba KS, Press OW, et al. Preliminary results of a phase II randomized study (ROMULUS) of polatuzumab vedotin (PoV) or pinatuzumab vedotin (PiV) plus rituximab (RTX) in patients (Pts) with relapsed/refractory (R/R) non-Hodgkin lymphoma (NHL). J Clin Oncol. (2020) 32:8519. doi: $10.1200 /$ jco.2014.32.15 suppl.8519

34. Novel Agents Continue to Advance in the Treatment Landscape of DLBCL. targetedonc (2020). Available online at: https://www.targetedonc.com/view/ novel-agents-continue-to-advance-in-the-treatment-landscape-of-dlbcl.

35. Buege MJ, Kumar A, Dixon BN, Tang LA, Pak T, Orozco J, et al. Management of mantle cell lymphoma in the era of novel oral agents. Ann Pharmacother. (2020) 54:879-98. doi: 10.1177/1060028020909117

36. Malenda A, Kołkowska-Leśniak A, Puła B, Długosz-Danecka M, Chełstowska M, Końska A, et al. Outcomes of treatment with dose-adjusted EPOCH-R or R-CHOP in primary mediastinal large B-cell lymphoma. Eur J Haematol. (2020) 104:59-66. doi: 10.1111/ejh.13337

37. Burkitt and Burkitt-Like Lymphomas: A Systematic Review. Springer (2020). Available online at: https://link.springer.com/article/10.1007/s11912-0200898-8.

38. Houillier C, Soussain C, Ghesquières H, Soubeyran $\mathrm{P}$, Chinot $\mathrm{O}$, Taillandier $\mathrm{L}$, et al. Management and outcome of primary CNS lymphoma in the modern era: an LOC network study. Neurology. (2020) 94:e1027-39. doi: 10.1212/WNL.0000000000008900

39. Ma H, Cheng B, Falchi L, Marchi E, Sawas A, Bhagat G, et al. Survival benefit in patients with peripheral T-cell lymphomas after treatments with novel therapies and clinical trials. Hematol Oncol. (2020) 38:51-8. doi: 10.1002/hon.2705

40. Brunner PM, Jonak C, Knobler R. Recent advances in understanding and managing cutaneous T-cell lymphomas. F1000Res. (2020) 9:F1000. doi: 10.12688/f1000research.21922.1

41. New Treatment Options in Advanced Stage Follicular Lymphoma: HemaSphere. (2020). Available online at: https://journals.lww.com/ hemasphere/Fulltext/2018/12000/New_Treatment_Options_in_Advanced_ Stage_Follicular.6.aspx
42. Hübel K, Ghielmini M, Ladetto M, Gopal AK. Controversies in the treatment of follicular lymphoma. Hemasphere. (2020) 4:e317. doi: 10.1097/HS9.0000000000000317

43. Ansell SM. Hodgkin lymphoma: a 2020 update on diagnosis, riskstratification, and management. Am J Hematol. (2020) 95:978-89. doi: 10.1002/ajh.25856

44. International Hodgkin Symposium. GHSG - German Hodgkin Study Group (2020). Available online at: https://en.ghsg.org/hodgkin-symposium.

45. Longley J, Johnson PWM. Options for first line therapy of Hodgkin lymphoma. Hematol Oncol. (2019) 37(S1):82-6. doi: 10.1002/hon.2597

46. Straus DJ, Długosz-Danecka M, Alekseev S, Illés A, Picardi M, Lech-Maranda E, et al. Brentuximab vedotin with chemotherapy for stage III/IV classical Hodgkin lymphoma: 3-year update of the ECHELON-1 study. Blood. (2020) 35:735-42. doi: 10.1182/blood.2019003127

47. Gallamini A, Tarella C, Viviani S, Rossi A, Patti C, Mulé A, et al. Early chemotherapy intensification with escalated BEACOPP in patients with advanced-stage Hodgkin lymphoma with a positive interim positron emission tomography/computed tomography scan after two ABVD cycles: long-term results of the GITIL/FIL HD 0607 trial. J Clin Oncol. (2018) 36:454-62. doi: 10.1200/JCO.2017.75.2543

48. Stephens DM, Li H, Schöder H, Straus DJ, Moskowitz CH, LeBlanc M, et al. Five-year follow-up of SWOG S0816: limitations and values of a PET-adapted approach with stage III/IV Hodgkin lymphoma. Blood. (2019) 134:1238-46. doi: 10.1182/blood.2019000719

49. Vassilakopoulos TP, Asimakopoulos JV, Konstantopoulos K, Angelopoulou MK. Optimizing outcomes in relapsed/refractory Hodgkin lymphoma: a review of current and forthcoming therapeutic strategies. Ther Adv Hematol. (2020) 11:2040620720902911. doi: 10.1177/2040620720902911

50. Terpos E, Engelhardt M, Cook G, Gay F, Mateos M-V, Ntanasis-Stathopoulos I, et al. Management of patients with multiple myeloma in the era of COVID 19 pandemic: a consensus paper from the European Myeloma Network (EMN). Leukemia. (2020) 34:2000-11. doi: 10.1038/s41375-020-0876-z

51. Rajkumar SV. Multiple myeloma: 2020 update on diagnosis, risk-stratification and management. Am J Hematol. (2020) 95:548-67. doi: 10.1002/ajh.25791

52. Suzuki K. Latest treatment strategies aiming for a cure in transplanteligible multiple myeloma patients: how I cure younger MM patients with lower cost. Int J Hematol. (2020) 111:512-8. doi: 10.1007/s12185-02002841-W

53. Bobin A, Gardeney H, Sabirou F, Gruchet C, Lévy A, Nsiala L, et al. The role of immunotherapy in non-transplant eligible multiple myeloma. Front Oncol. (2020) 10:676. doi: 10.3389/fonc.2020.00676

54. Gil-Sierra MD, Gimeno-Ballester V, Fenix-Caballero S, Alegre-Del Rey EJ. Network meta-analysis of first-line treatments in transplantineligible multiple myeloma patients. Eur J Haematol. (2020) 105:56-65. doi: 10.1111/ejh.13407

55. Chari A, Martinez-Lopez J, Mateos M-V, Bladé J, Benboubker L, Oriol A, et al. Daratumumab plus carfilzomib and dexamethasone in patients with relapsed or refractory multiple myeloma. Blood. (2019) 134:421-31. doi: 10.1182/blood.2019000722

56. Bazarbachi AH, Al Hamed R, Malard F, Harousseau J-L, Mohty M. Relapsed refractory multiple myeloma: a comprehensive overview. Leukemia. (2019) 33:2343-57. doi: 10.1038/s41375-019-0561-2

Conflict of Interest: The authors declare that the research was conducted in the absence of any commercial or financial relationships that could be construed as a potential conflict of interest.

Copyright (c) 2021 Ibrahim, Noun, Khalil and Taher. This is an open-access article distributed under the terms of the Creative Commons Attribution License (CC BY). The use, distribution or reproduction in other forums is permitted, provided the original author(s) and the copyright owner(s) are credited and that the original publication in this journal is cited, in accordance with accepted academic practice. No use, distribution or reproduction is permitted which does not comply with these terms. 